Research Article

\title{
Rapid Estimation of Excess Mortality during the COVID-19 Pandemic in Portugal -Beyond Reported Deaths
}

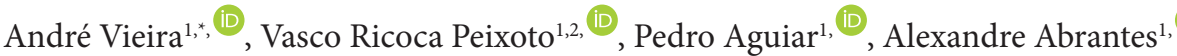 \\ ${ }^{1}$ Public Health Research Centre, NOVA National School of Public Health, Universidade NOVA de Lisboa, Portugal \\ ${ }^{2}$ Public Health Unit, North Lisbon Health Centers, Lisbon, Portugal
}

\section{ARTICLE INFO}

Article History

Received 14 May 2020

Accepted 20 June 2020

Keywords

Coronavirus

disease outbreaks

mortality

pandemics

Portugal

\begin{abstract}
Background: One month after the first COVID-19 infection was recorded, Portugal counted 18,051 cases and 599 deaths from COVID-19. To understand the overall impact on mortality of the pandemic of COVID-19, we estimated the excess mortality registered in Portugal during the first month of the epidemic, from March 16 until April 14 using two different methods.

Methods: We compared the observed and expected daily deaths (historical average number from daily death registrations in the past 10 years) and used 2 standard deviations confidence limit for all-cause mortality by age and specific mortality cause, considering the last 6 years. An adapted Auto Regressive Integrated Moving Average (ARIMA) model was also tested to validate the estimated number of all-cause deaths during the study period.

Results: Between March 16 and April 14, there was an excess of 1255 all-cause deaths, 14\% more than expected. The number of daily deaths often surpassed the 2 standard deviations confidence limit. The excess mortality occurred mostly in people aged $75+$. Forty-nine percent (49\%) of the estimated excess deaths were registered as due to COVID-19, the other 51\% registered as other natural causes.

Conclusion: Even though Portugal took early containment measures against COVID-19, and the population complied massively with those measures, there was significant excess mortality during the first month of the pandemic, mostly among people aged $75+$. Only half of the excess mortality was registered as directly due do COVID-19.

\section{KEY POINTS}

- An Excess Mortality (EM) of 1255 deaths were estimated 1 month after the first death classified by COVID-19, and it would probably be more if the government had not taken early action.

- The age group where a significant increase in mortality was noted was above 75 years.

- $51 \%$ of the EM was due to natural causes other than COVID-19.
\end{abstract}

(C) 2020 The Authors. Published by Atlantis Press International B.V. This is an open access article distributed under the CC BY-NC 4.0 license (http://creativecommons.org/licenses/by-nc/4.0/).

\section{INTRODUCTION}

The COVID-19 pandemic is expected to cause Excess Mortality (EM) throughout 2020, both directly, due to deaths among those infected, and indirectly, due to patients' not seeking health care for fear of becoming infected by COVID-19, or due to the inability of healthcare system to provide effective services to patients other than those with COVID-19. The economic and social impact of the pandemic could also contribute to longterm EM [1].

According to Johns Hopkins University, by April 15, 2020, the COVID-19 virus had infected nearly 2 million people and killed more than 128,000 people worldwide [2]. EuroMOMO reports a

"Corresponding author.Email: aam.vieira@ensp.unl.pt Data availability statement: The datasets generated and/or analysed during the current study are available in the SICO-eVm repository (https://evm.min-saude.pt/\#shiny-tabq_total) and Directorate-General of Health) daily Situation Reports (https://www.dgs.pt/ informacao-e-comunicacao/historico-de-destaques.aspx). significant increase in the number of deaths caused by COVID-19 in several countries such as Spain and Italy [3]. Other analyzes, for countries like England, France, Switzerland and the Netherlands already presented considerable excess mortality as of at that time [4]. These values would probably have been much higher if no action had been taken. However, making comparisons between different methods can be challenging, since the methods used and periods considered vary considerably, from study to study.

On March 16, 2020, the first death due to COVID-19 was registered in Portugal, 14 days after the first confirmed case of infection. In March 2020, 187 people died of COVID-19, or 2.3\% of the 8521 confirmed patient cases, a cumulative incidence of around 80 cases per 100,000 inhabitants and a lethality rate of $2.3 \%$. In Portugal, most deaths by COVID-19 reported so far have occurred in individuals with underlying health conditions or at older ages [5].

This article estimates excess mortality during the first month of recorded deaths by COVID-19. 


\section{MATERIALS AND METHODS}

Mortality data was extracted from the Portuguese Death Certificate Information System (SICO-eVM) [6]. Data on the number of COVID-19 reported deaths in Portugal were extracted from information in the Directorate-General of Health daily Situation Reports [7].

For estimating total EM, we calculated the historical average and respective Standard Deviation (SD) of the number of daily all-cause mortality for the last 10 years, between January 1 and April 14. To estimate the excess mortality by age and cause (natural and external), we used only the last 6 years average, because the information was not available for earlier years.

We considered Relevant Excess Mortality (REM) when the daily observed values exceed the estimated average value of deaths for each day plus corresponding 2 SDs or if they exceed the limits of the $95 \%$ confidence interval in the Auto Regressive Integrated Moving Average (ARIMA) model. The REM calculation method has been used in similar studies $[8,9]$.

To validate the EM calculated on the basis of historical daily deaths, from all causes, we compared it with the estimated results obtained with an ARIMA model $(1,1,5)$ adjusted to the time series until April 14,2020 . We modeled a time series including the observed mortality from January 1, 2010 to March 15, 2020 and the historical average after that day from March 16, 2020 until 14 April 2020. This cut-off point (March 16) was the date of first reported COVID-19 death and the close inversion in mortality trend. We compared the observed and modeled expected mortality for the pandemic period and the respective $95 \%$ confidence intervals. The model was adjusted with the SPSS program, with a determination coefficient of $R^{2}=0.801$, Ljung-Box test not statistically significant, Autocorrelation Function and Partial Autocorrelation Function not statistically significant in the residues, and estimates of the auto parameters - statistically significant regression and moving averages $(p<0.01)[10]$.

\section{RESULTS}

\subsection{All-cause Excess Mortality}

Between March 16 and April 14, 2020, there was an excess of 1255 deaths over the expected, based on average daily mortality during the previous 10 years, an excess mortality of $13.7 \%$. The number of deaths observed exceeded the defined threshold of REM in 14 days of the study period, totaling 242 REM (Figure 1).

During the 10 years' time-series of mortality data, March and April showed declining mortality in relation to January and February. In 2020, there is an inversion of this negative trend as of March 11, with an EM above the average of the previous 10 years, exceeding the average threshold plus 2 SD, as of March 24, 2020.

\subsection{Excess Mortality by Age}

Almost all EM was detected among people aged 75 years or more. Between March 1 and April 14, 2020, there was an EM of 1030 deaths in people aged $75+$, compared to the daily averages of deaths in this age group, in the last 6 years. For this age group, the number of deaths observed exceeded the defined threshold of REM in 11 days of the study period, totaling 201 REM.

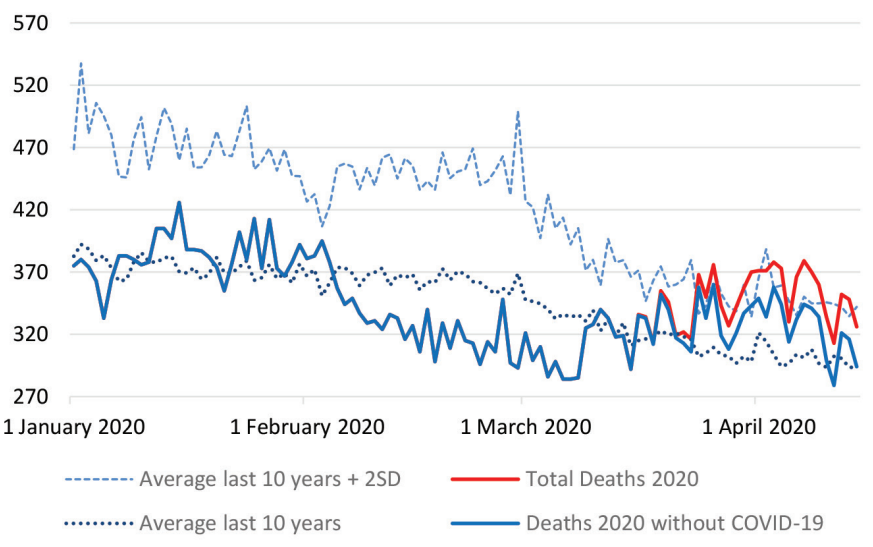

Figure 1 All-cause mortality between 1st January and 14th April 2020.

In the same period, only 67 deaths were estimated above the historical average in the age group between 65 and 74 years old and EM was not identified in any other age group.

\subsection{Excess Mortality by Cause}

The COVID-19 reported deaths are included in deaths due to natural causes. Between March 16 and April 14, there was an EM of 1281 deaths from natural causes, based on deaths registered in the last 6 years (Table 1 and Figure 2).

The number of deaths due to natural causes exceeded the average $+2 \mathrm{SD}$ limit for the last 6 years in 19 days, totaling 566 deaths in REM. Between March 16 and April 14, there was a 15.2\% increase in deaths from natural causes and a $57 \%$ reduction in deaths from external causes compared to the averages observed in the previous 6 years.

\subsection{ARIMA Modelling}

Forty-nine percent of excess deaths were caused by COVID-19 and another $51 \%$ were attributed to other natural causes.

Comparing the observed deaths with those modeled for March and April, we observed an EM from March 16, exceeding the upper limit of the confidence interval in the last days of March and the first days of April (Figure 3). There is also a tendency toward a reduction in mortality in April, as some effect of the confinement measures is already expected to have occurred. Between March 16 and April 14, there was an excess of 1214 deaths in relation to the deaths those estimated for a situation in which there was no epidemic. 10,445 deaths were observed and the chronological model estimates that 9231 deaths would have been recorded, had there not been a pandemic. Excess mortality was similar in the two applied methods suggesting that results of this study are robust.

The estimated excess mortality has two components: $49 \%$ of excess deaths were caused by COVID- 19 and another $51 \%$ were attributed to other causes. In the study period, 599 deaths were registered by COVID-19, so we estimate that the excess of non-COVID-19 Mortality (EMnC) was 615 deaths (1214 - 599), due to other causes natural causes not directly related to the pandemic. 
Table 1 Overall description by all-cause, age and natural/external cause

\begin{tabular}{|c|c|c|c|c|c|}
\hline & $\begin{array}{l}\text { Expected } \\
\text { deaths }(n)\end{array}$ & $\begin{array}{l}\text { Observed deaths } \\
\quad \text { in } 2020(n)\end{array}$ & $\begin{array}{c}\text { Difference } \\
\text { between } \\
\text { observed and } \\
\text { expected }(n)\end{array}$ & $\begin{array}{c}\text { Expected } \\
\text { deaths }+2 \text { SD } \\
(n)\end{array}$ & $\begin{array}{c}\text { Difference between } \\
\text { observed and } \\
\text { expected deaths }+2 \\
\text { SD }(n)\end{array}$ \\
\hline \multicolumn{6}{|l|}{ All-cause mortality } \\
\hline \multicolumn{6}{|l|}{ By month } \\
\hline January & 11,607 & 11,863 & +256 & 14,666 & -2803 \\
\hline February & 10,564 & 9615 & -946 & 13,002 & -3387 \\
\hline March & 9967 & 10,069 & +102 & 11,626 & -1557 \\
\hline April (1st to 14th) & 4223 & 4971 & +748 & 4901 & +71 \\
\hline \multicolumn{6}{|l|}{ By week } \\
\hline 16th to 23 rd March & 2547 & 2641 & +94 & 2918 & -277 \\
\hline 24th to 31st March & 2420 & 2833 & +413 & 2782 & +51 \\
\hline 1st to 7th of April & 2135 & 2568 & +433 & 2503 & +65 \\
\hline 8th to 14th of April & 2088 & 2403 & +315 & 2399 & +4 \\
\hline \multicolumn{6}{|l|}{ Age } \\
\hline \multicolumn{6}{|l|}{$65-74$ years old } \\
\hline January & 1641 & 1684 & +43 & 2120 & -436 \\
\hline February & 1381 & 1313 & -68 & 1774 & -461 \\
\hline March & 1390 & 1411 & +21 & 1850 & -439 \\
\hline April (1st to 14th) & 630 & 676 & +46 & 818 & -142 \\
\hline \multicolumn{6}{|l|}{ +75 years old } \\
\hline January & 8959 & 8617 & -342 & 11,719 & -3102 \\
\hline February & 7470 & 7033 & -437 & 9253 & -2220 \\
\hline March & 7099 & 7479 & +380 & 8450 & -971 \\
\hline April (1st to 14th) & 3042 & 3692 & +650 & 3644 & +48 \\
\hline \multicolumn{6}{|l|}{ Cause } \\
\hline \multicolumn{6}{|l|}{ Natural causes } \\
\hline \multicolumn{6}{|l|}{ By month } \\
\hline January & 11,031 & 10,608 & -423 & 13,913 & -3305 \\
\hline February & 9538 & 8786 & -752 & 11,119 & -2333 \\
\hline March & 8968 & 9347 & +379 & 10,375 & -1028 \\
\hline April (1st to 14 th) & 3892 & 4609 & +717 & 4145 & +464 \\
\hline \multicolumn{6}{|l|}{ By week } \\
\hline 16th to 23 rd March & 2278 & 2440 & +162 & 2624 & -184 \\
\hline 24th to 31st March & 2207 & 2609 & +402 & 2555 & +54 \\
\hline 1st to 7th of April & 1980 & 2360 & +380 & 2107 & +253 \\
\hline 8th to 14th of April & 1912 & 2249 & +337 & 2038 & +211 \\
\hline \multicolumn{6}{|l|}{ External causes } \\
\hline \multicolumn{6}{|l|}{ By month } \\
\hline January & 166 & 117 & -49 & - & - \\
\hline February & 138 & 93 & -45 & - & - \\
\hline March & 148 & 70 & -78 & - & - \\
\hline April (1st to 14 th) & 61 & 34 & -27 & - & - \\
\hline \multicolumn{6}{|l|}{ By week } \\
\hline 16th to 23rd March & 40 & 22 & -18 & - & - \\
\hline 24th to 31st March & 36 & 22 & -14 & - & - \\
\hline 1st to 7 th of April & 44 & 30 & -14 & - & - \\
\hline 8th to 14 th of April & 44 & 31 & -13 & - & - \\
\hline
\end{tabular}

Expected deaths correspond to the average mortality based on the last 10 or 6 years. The 2 Standard Deviations (SDs) were calculated for each subgroup analysis.

\section{DISCUSSION}

The findings of this study suggest an excess mortality during the first month of the COVID-19 pandemic in Portugal, with a gradual reduction of the trend from the second week in April.

The results seem robust as they are consistent using two different estimate methods: (a) comparing observed and expected deaths, based on the calculation of the historical averages and $2 \mathrm{SD}$ of death records for the last 10 years, and (b) using the ARIMA model, filling the historical average from the date were forecast would begin, we included historical data in ARIMA forecasting making the prediction and confidence levels closer to reality considering the actual year and the previous ones.

Our excess mortality estimates are conservative, since expected deaths are influenced by the previous years and the present year registered lower mortality than expected in February and early March. 


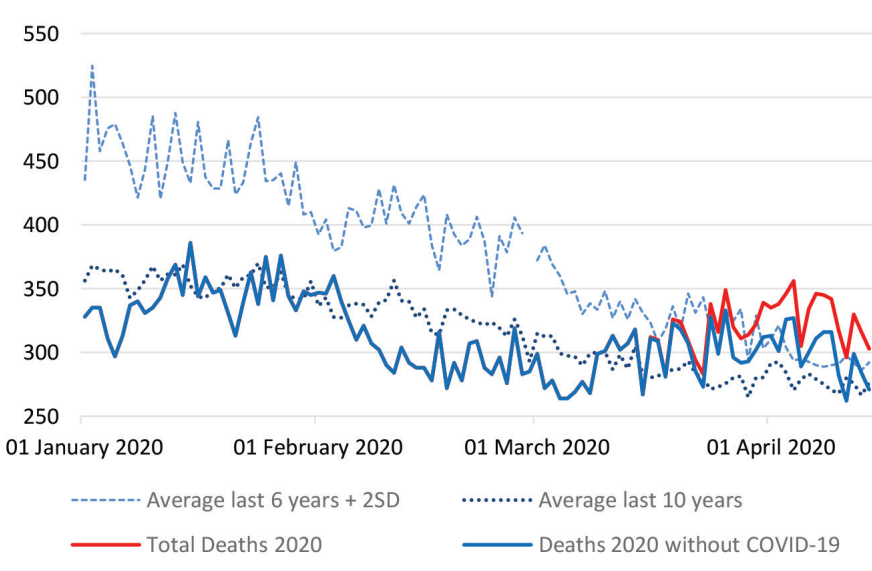

Figure $2 \mid$ Mortality by natural cause between 1st January and 14th April 2020.

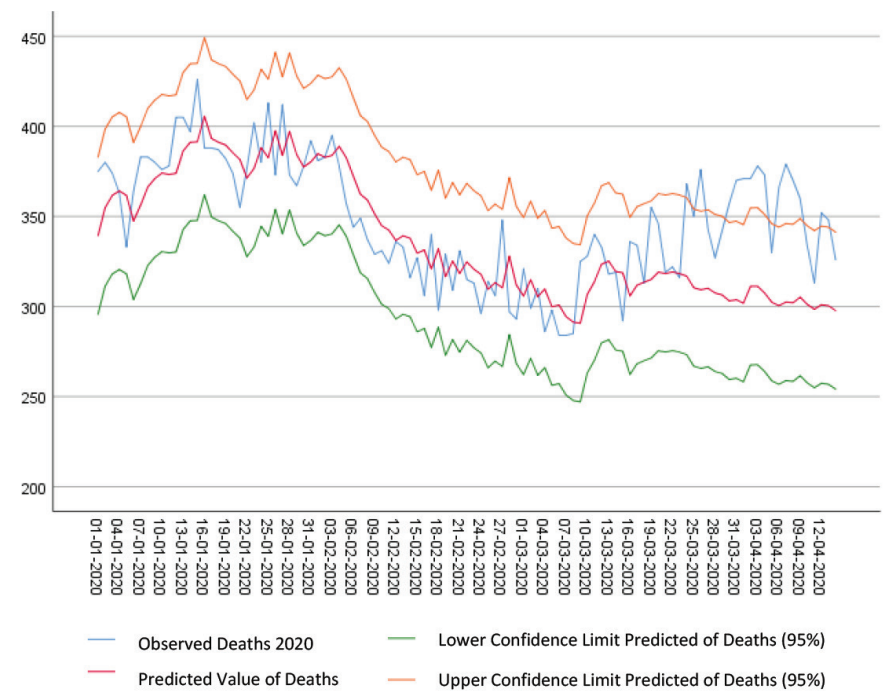

Figure 3 Evolution of mortality analyzed using the ARIMA model.

In addition, during the study period there was a significant reduction in the number of injury related deaths, namely those associated with traffic accidents, due to severe mobility restrictions imposed by the Authorities [11].

The results are also in line with the estimates made by other excess mortality studies carried out in Portugal. Nogueira et al. [12] estimated an EM between 2400 to 4000 deaths between March 1 and April 22. These differences can be attributed to different methods and time windows used.

These results are also in line with other and international studies, namely those of EuroMOMO [3]. Another study reported significant excessive mortalities in New York City $(+289 \%)$ and in countries like Spain (+66\%), England and Wales (+33\%), the Netherlands $(+33 \%)$ and Belgium (+25\%)[4]. Difference may be explained, by different epidemic starting times, in different countries, the time at which each country adopted different confinement measures, and different compliance rates [13].

Our study shows a decline in excess mortality 2 weeks after it implemented stringent confinement measures, with which the population complied. Other countries like England, Spain, Italy and the Netherlands have maintained very high levels of EM in weeks 13 and 14 of the respective epidemics [3].

Our study suggests a concentration of excess mortality among those aged $75+$. EuroMOMO also registers excess mortality for age groups between 15 and 64 years old and above 65 . The difference may be related to the high lethality of the COVID-19 virus for patients aged $80+(12.4 \%)$ [14] and with the vulnerability of this population to changes in supply and demand for health care itself.

This study showed that $51 \%$ of the registered excess mortality was due to other natural causes, not classified as COVID-19 (EMnC). This may be explained by: (a) some patients may have died with COVID-19 died at home, or at long-term care institution, without having had a COVID-19 test; other patients, with serious conditions, may not have sought hospital care, for fear of being infected, or did seek hospital care but did not get the full attention needed, because manpower and equipment were dedicated to the care of COVID-19 patients.

Under ascertainment may have been a problem during the first period of the study period and a study from the Imperial College of London about under-ascertainment estimated Portugal to report $36 \%$ of estimated number of infections [15]. This became less of a problem by April, when Portugal adopted a generous testing strategy, including tests in long term care institutions and even at the morgue. Finally, Portugal has an inclusive definition for classifying deaths as due to COVID-19, accepting the diagnosis in the absence of a confirmation test [16].

A study by Rui Santana et al. [17] supports the hypothesis that patients reduced emergency visits, since it showed that, in March 2020 , there was a $48 \%$ drop in the demand for emergency services and a reduction of more than 144,000 emergency episodes, for patients with a higher priority of care (yellow and red bracelets), when compared to previous years.

Some international studies also reported EM by non COVID-19 in different countries and found it varying from $20 \%$ to $60 \%$, in Spain, Belgium France, England and Wales, Italy, the Netherlands, Switzerland and Sweden, which is in line with the results presented in this study $[18,19]$.

Our study shows EM due to natural causes were superior to total EM. This difference partly explained by a significant reduction in the number of injury related deaths, namely those associated with traffic accidents, due to severe mobility restrictions imposed by the Authorities [11].

This study has some limitations. SICO database undergoes updates several days after first registration, which is one of the reasons why it is safer to carry out this analysis with some time lag. Also, in the initial phase of the pandemic many deaths may have occurred without having been identified with COVID-19. It was also not possible to obtain a greater detail, mainly in the older populations, due to the database obtained from the deaths being previously classified with the classes analyzed in this document.

Overall, despite heterogeneous methods and findings of different studies, our results add to the body of evidence created around COVID-19 excess mortality. 


\section{CONCLUSION}

Between March 16 and April 14, 2020, there was an excess of 1255 deaths over the expected, based on average daily mortality during the previous 10 years, an excess mortality of $13.7 \%$. The number of deaths observed exceeded the defined threshold of REM in 14 days of the study period, totaling 242 REM.

Almost all EM was detected among people aged 75 years or more. Between March 1 and April 14, 2020, there was an EM of 1030 deaths in people aged $75+$, compared to the daily averages of deaths in this age group, in the last 6 years. For this age group, the number of deaths observed exceeded the defined threshold of REM in 11 days of the study period, totaling 201 REM.

Forty-nine percent of excess mortality were caused by COVID-19 and another $51 \%$ were attributed to other natural causes. Collateral excess mortality by non COVID-19 needs further investigation.

One month after the first death recorded by COVID-19 in Portugal, an EM is observed for all-cause mortality, mainly in the age groups above 75 years of age. Portugal registers less EM than many other countries. This may be due to the Authorities having decreed stringent confinement measures early and the high levels of compliance of the population.

As we enter a phase of deconfinement, it is necessary to maintain a high level of surveillance to intervene early and with precision wherever there are signs of any excess morbidity or mortality by COVID-19.

\section{CONFLICTS OF INTEREST}

The authors declare they have no conflicts interest.

\section{AUTHORS' CONTRIBUTION}

AV contributed in conceptualization, methodology, formal analysis and writing (original draft). VRP contributed in methodology, formal analysis and validation. PA contributed in formal analysis and validation. AA contributed in term, conceptualization, writing (review and editing).

\section{FUNDING}

No financial support was provided.

\section{REFERENCES}

[1] Council of the EU. Report on the comprehensive economic policy response to the COVID-19 pandemic [press release]. Brussel: Council of the EU; 2020. Available from: https://www. consilium.europa.eu/it/press/press-releases/2020/04/09/reporton-the-comprehensive-economic-policy-response-to-the-covid19-pandemic/pdf.

[2] Johns Hopkins University \& Medicine. COVID-19 Dashboard by the Center for Systems Science and Engineering (CSSE) at Johns Hopkins University (JHU). Baltimore: Johns Hopkins University \& Medicine; 2020. Available from: https://coronavirus.jhu.edu/ map.html.
[3] EUROMOMO. EuroMOMO Bulletin, Week 15. Copenhagen: EUROMOMO; 2020. Available from: https:/www.euromomo.eu/ bulletins/2020-15/.

[4] Wu J, McCann A, Katz J, Peltier E. 28,000 Missing deaths: tracking the true toll of the coronavirus outbreak. NY, USA: New York Times; 2020.

[5] European Centre for Disease Prevention and Control. Download today's data on the geographic distribution of COVID-19 cases worldwide [Internet]. Solna: European Centre for Disease Prevention and Control; 2020 (cited April 24, 2020).

[6] Sistema de Informação dos Certificados de Óbito - Vigilância de Mortalidade [Internet]. 2020. Available from: https://evm.minsaude.pt/ (cited April 15, 2020).

[7] Direção Geral da Saúde (DGS). Novo Coronavírus COVID-19 - Relatório de Situação. Lisboa: Direção Geral da Saúde; 2020 (cited April 15, 2020).

[8] Green HK, Andrews NJ, Bickler G, Pebody RG. Rapid estimation of excess mortality: nowcasting during the heatwave alert in England and Wales in June 2011. J Epidemiol Community Health 2012;66;866-8.

[9] CEBM. Tracking mortality over time - Update 28th April 2020. Oxford: CEBM; Available from: https://www.cebm.net/covid-19/ tracking-mortality-over-time/ (updated April 21, 2020).

[10] Tabachnick BG, Fidell LS. Using multivariate statistics, 6th ed. Boston: Allyn \& Bacon; 2012.

[11] INSA. Boletim de Vigilância Epidemiológica da Gripe - Época 2019/2020, Semana 14. Lisboa: INSA; 2020.

[12] Nogueira PJ, Nobre MA, Nicola PJ, Furtado C, Vaz Carneiro A. Excess mortality estimation during the COVID-19 pandemic: preliminary data from Portugal. Acta Med Port 2020;33;376-83.

[13] Public Health England. All-cause mortality surveillance - 02 April 2020 - Week 14 report (up to week 13 data). In: Immunisation \& countermeasures division, National Infection Service. Lisboa: Public Health England; 2020. p. 1.

[14] Peixoto VR, Vieira A, Abrantes AV. Um mês em tempos de COVID-19. London: Escola Nacional de Saúde Pública. Universidade Nova de Lisboa; 2020. http://hdl.handle.net/10362/97666

[15] Bhatia S, Cori A, Parag KV, Mishra S, Cooper LV, Ainslie KEC, et al. Short-term forecasts of COVID-19 deaths in multiple countries. Imperial College COVID-19 response team: the WHO Collaborating Centre for Infectious Disease Modelling within the MRC Centre for Global Infectious Disease Analysis, J-IDEA, Imperial College London [Internet]. 2020. Available from: https://mrc-ide.github.io/covid19-short-term-forecasts/index. html\#authors (accessed May 6, 2020).

[16] Kotowicz A. Os países contam as mortes por Covid de forma diferente. Contagem em Portugal considera mais casos. Lisboa: Observador; 2020 (accessed April 1, 2020).

[17] Santana R, Rocha J, Sousa J, Soares P. A procura de serviços de urgência/ emergência hospitalar: tendências durante o primeiro mês de resposta à COVID-19. Lisboa: Escola Nacional de Saúde Pública, Universidade NOVA de Lisboa; 2020.

[18] Office for National Statistics. Deaths registered weekly in England and Wales, provisional: week ending 17 April 2020. London: Office for National Statistics; 2020. Available from: https://www. ons.gov.uk/peoplepopulationandcommunity/birthsdeathsandmarriages/deaths/bulletins/deathsregisteredweeklyinenglandandwalesprovisional/weekending17april2020\#main-points.

[19] Wu J, McCann A, Katz J, Peltier E. 40,000 Missing deaths: tracking the true toll of the coronavirus outbreak. NY, USA: New York Times; 2020 . 